\title{
Well Neonate Due For Discharge In Low Resource Setting Must Be Screened For Significant Hyperbilirubinemia
}

Nasuna Carolyn

Makerere University College of Health Sciences

Yaser Abdallah ( $\square$ yasam786@hotmail.com )

Makerere University College of Health Sciences https://orcid.org/0000-0002-8674-1736

Karamagi Charles

Makerere University College of Health Sciences

Mugalu Jamiru

Makerere University College of Health Sciences

Research article

Keywords: Significant Hyperbilirubinemia, transcutaneous bilirubinometer

Posted Date: June 16th, 2020

DOI: https://doi.org/10.21203/rs.3.rs-16547/v2

License: @ (i) This work is licensed under a Creative Commons Attribution 4.0 International License.

Read Full License 


\section{Abstract}

Background: Due to lack of comprehensive postnatal care; neonates in low resource settings are at high risk for significant hyperbilirubinemia (SHB) and its complications. We conducted a study to determine the prevalence of SHB, factors associated with it and performance of transcutaneous bilirubin (TCB) measurement compared to visual inspection in identifying these neonates.

Methods: We conducted a cross sectional study over a one month period involving 235 neonates 24 to 72 hours of age who were due for discharge in the postnatal ward of Mulago Hospital. Relevant data was captured. Neonates with SHB were referred for treatment. Data was entered in to Epi-data version 3.0 then exported to STAT 14.0 software and analyzed. P-value of $<0.05$ was considered significant with confidence interval of $95 \%$.

Results: Thirty two (13.6\%) of the participants had SHB and Three (1.3\%) had bilirubin levels at/above exchange transfusion threshold. The means serum bilirubin level among neonates with SHB was $240 \mu \mathrm{mol} / \mathrm{I}$ (range 132-481.4 $\mu \mathrm{mol} / \mathrm{l})$. Possible causes for SHB included; ABO/Rhesus discordance 11 (34.4\%), possible sepsis $8(25 \%)$ due to high CRP without any explanation, significant weight loss 2 (6.25\%), cephalohematoma $2(6.25 \%)$ and twelve (37.5\%) no immediate cause was identified. Significant hyperbilirubinemia was independently associated with CRP $\geq 10 \mathrm{mg} / \mathrm{l}$ (AOR 3.96, Cl 1.23-12.73, p 0.021), ABO discordance (AOR 3.67, Cl 1.28-10.49, p 0.015), jaundice in a previous baby (AOR 3.565, Cl 1.10$11.51, \mathrm{p} 0.034$ ) and time of initiation of feeds $>1$ hour (AOR 2.74, $\mathrm{Cl} 1.10-6.90, \mathrm{p} 0.007$ ). The sensitivity, specificity, positive and negative predictive values of TCB were $96.5 \%, 84.6 \%, 47.5 \%$ and $99.4 \%$ respectively compared to $31.2 \%, 98.5 \%, 76.9 \%$ and $90 \%$ respectively for visual assessment.

Conclusions: Among well neonates in the post natal ward approximately 1 in 10 have SHB and 1 in 100 have bilirubin level at exchange transfusion threshold between 24 and 72 hours of age hence screening for SHB among such neonates should be emphasized. Transcutaneous bilirubinometry is a suitable screening tool since it identified majority of neonates with SHB. Early initiation of feeding should be promoted. Screening for possible sepsis in neonates with significant hyperbilirubinemia without identifiable reason should be considered.

\section{Background}

Jaundice affects $60 \%$ to $80 \%$ of all neonates majority of whom no intervention will be necessary. About $10 \%$ of all newborns will develop significant jaundice to warrant close monitoring and treatment (1-3). Presence of underlying factors including prematurity, sepsis, blood group incompatibility, G6PD deficiency, inadequate feeding among others contribute to some neonates developing severe neonatal jaundice (SNJ) necessitating hospital readmission $(4,5)$. Severe neonatal jaundice is a leading cause for hospitalization (35\%) in the first month of life $(1,5)$.

Severe neonatal jaundice needs early identification and prompt management in order to prevent progression in to brain dysfunction (acute bilirubin encephalopathy (ABE)) and death. Neonates who 
survivors following $A B E$ have been observed to be at increased risk for disability $(6,7)$. It is estimated globally 481000 term/ near term neonates are affected by SNJ annually of whom 114000 die and 63000 survive with disability (8). The majority of neonates affected by SNJ are in Low and Middle income countries (LMICS) $(1,5,8,9)$.

Neonates with SNJ need urgent intensive phototherapy while those with signs of ABE besides intensive phototherapy may progress to needing exchange transfusion at the shortest time possible in order to prevent disability and death. The highest burden of exchange transfusion and mortality associated with neonatal jaundice are in the LMICs; these have been attributed to health system bottlenecks $(1,9)$.

Available evidence shows that risk assessment for SNJ along with carefully timed estimation of bilirubin level and prompt intervention significantly reduce hospital readmissions, occurrence of severe jaundice, need for exchange transfusion and associated disability in the developed countries $(10,11)$.

Whereas the WHO recommends 24 hour hospital stay after uncomplicated delivery, assessing for jaundice prior to discharge, follow up review within 72 hours and again within the first week $(12,12)$; implementation of these recommendation in LMICS has been challenging.

At the Mulago National referral hospital, stable babies are not screened for jaundice and are discharged early. The prevalence of significant hyperbilirubinemia (SHB) among these neonates and associated factors are not known. We conduct this study to determine the prevalence of SHB among stable neonates due for discharge, factors associated with it and how transcutaneous bilirubinometry performed in identifying such neonates compared to visual inspection.

\section{Methods}

Study Setting: This study was conducted at the postnatal ward of the Mulago National Referral Hospital. This Hospital is Uganda's National Referral Hospital and training hospital for Makerere College of Health Sciences. The hospital records 31000 deliveries annually.

After delivery stable neonates are kept by the mother's side in the post natal ward where the mother-baby pair are observed for 6-12 hours for normal vaginal delivery and 72 hours for cesarean delivery.

In the post natal ward exclusive breast feeding is encouraged and health education is given to the mothers. Neonates are assessed by midwives while the mothers by the medical doctor from the obstetric team; once the neonate and mother are thought to be stable they are discharged.

If there is any concern related to the neonate then a doctor is notified; unwell neonates are transferred to the Special Care Baby Unit (SCBU) for further assessment and care. The postnatal ward does not have a structured protocol for review of the neonate at the mother's bedside and for those ready for discharge.

Study Population: well neonates 24 to 72 hours of age due for discharge. 
Sample size: The sample size for prevalence was calculated using Kish Leslie formula for cross sectional studies $N=Z a^{2} P(1-P) / W^{2}$ assuming expected prevalence for severe neonatal jaundice of $34 \%$ (13), as observed among neonates admitted in Kenya; the sample size needed to determine prevalence of significant hyperbilirubinemia with $95 \%$ level of confidence was 350 . Considering we were recruiting from 24 hours of age, majority of our study participant would be born by caesarean section since most vaginally delivered babies would have been discharged. With approximately 31000 annual deliveries and $25 \%$ cesarean section (14), available population to us over 1 month period would be approximately 646 . Estimating sample size for available population using Open-Epi for population survey at $95 \% \mathrm{Cl}$, we would need 227 babies. Assuming a 3.5\% for incompleteness of data our final sample size was 235 .

Study Procedure: Parents or primary care givers of the neonates who meet study criteria were given information about the study and informed consent was obtained by the principal investigator/ research assistants. Data capturing sheet was used to enter relevant information. Risk factors considered in the data sheet included blood group, mode of delivery, risk for sepsis, history of jaundice in previous child, time of initiating feeds and bruising and cephalohematoma, weight loss were captured.

History was taken and study neonates were examined by the principal investigator or research assistant. Gestational age was determined using mother's records if available and the New Ballard Score (15) conducted by the trained research assistant. Study neonates were assessed for jaundice by visual inspection and graded as per the Kramer rule (16), this was done by a trained research assistant just prior to blood sampling. Transcutaneous Bilirubin (TCB) measurement was done by the principal investigator using a calibrated Draeger JM103 transcutaneous bilirubinometer over the sternum. This was done within 30 minutes of blood collection.

Mother's documented blood group was ascertained and for those with no blood group documented; blood grouping was done.

For all study neonates blood samples were collected by a research assistant, $0.5 \mathrm{ml}$ through heel prick for total serum bilirubin and $0.5 \mathrm{mls}$ by venipuncture for the blood grouping and C-reactive protein. The blood collection sites were cleaned with $70 \%$ alcohol and allowed to air dry. Blood samples were dispensed into 2 EDTA free containers and transported within one hour to Mulago chemistry laboratory. Total serum bilirubin was determined by diazo colorimetric method using COBAS 6000 bilirubin analyzed.

Neonates found to have SHB i.e any level $20 \mu \mathrm{mol} / \mathrm{I}$ within threshold or greater on the age specific bilirubin nomogram (Using the neonatal academic hospitals' consensus guidelines for South African hospitals and primary care facilities) (17) were referred to the SCBU for further management.

Data management and analysis: Information captured in the data sheet was checked by the principle investigator for completeness and accuracy. The data sheets were stored in a locker.

Data were entered into the computer using Epi-data version 3.0 and thereafter exported into STATA version 14.0 for analysis with the help of a Bio-statistician. Data was checked for errors, cleaned and 
coded before analysis. Baseline characteristic of study participants were summarized in a table. The prevalence of SHB was computed as a ratio of neonates with total serum bilirubin warranting treatment to total number of study neonates. Univariate analysis was conducted for continuous variables. Multivariate analysis for factors associated with SHB was determined in a stepwise manner.

$P$ values of $<0.05$ were considered significant and confidence interval of $95 \%$ was used. Though a $2 \times 2$ table; the performance of transcutaneous bilirubinometer and visual assessment were determine. The sensitivity, specificity, positive and negative predictive values were computed. Results were summarized in tables.

\section{Results}

Between $29^{\text {st }}$ March 2017 and $3^{\text {rd }}$ May 2017 a total of 235 neonates were enrolled. The average age of the neonates at enrollment was $49( \pm 14.4)$ hours. Mean birth weight was $3.18 \mathrm{~kg}$ (range 1.9-4.6kg). Majority were exclusively breast fed (96\%). Visible jaundice was apparent in 43(18.3\%) neonates graded as Kramer grade 3, 2 and 1 in 6, 7 and 30 participants respectively. Thirty two (13.6\%) of the neonates had SHB (table 1). The mean TSB among neonates with SHB was $240 \mu \mathrm{g} / \mathrm{l}(\mathrm{range} 132-481 \mu \mathrm{mol} / \mathrm{l})$. Three of the study participants with SHB had TSB $<170 \mu \mathrm{mol} / \mathrm{l}$ but qualified for phototherapy based on risk assessment.

'able 1: Baseline characteristics and Factors associated with significant hyperbilirubinemia 


\begin{tabular}{|c|c|c|c|c|}
\hline \multirow[t]{2}{*}{ VARIABLES } & \multicolumn{2}{|c|}{$\begin{array}{c}\text { Significant } \\
\text { hyperbilirubinemia }\end{array}$} & \multirow[t]{2}{*}{$\begin{array}{r}\text { OR } \\
(95 \% \mathrm{CI})\end{array}$} & \multirow[t]{2}{*}{$\begin{array}{c}\text { p- } \\
\text { value }\end{array}$} \\
\hline & No (203) & Yes (32) & & \\
\hline \multicolumn{5}{|l|}{ Sex } \\
\hline Male & $108(85.7)$ & 18(14.3) & $\begin{array}{l}1.13(0.53- \\
2,39)\end{array}$ & 0.748 \\
\hline Female & $95(87.1)$ & $14(12.9)$ & & \\
\hline \multicolumn{5}{|l|}{ Gestational age } \\
\hline$\leq 37+6$ & $28(80.0)$ & $7(20.0)$ & $\begin{array}{c}1.85(0.73- \\
4.67)\end{array}$ & 0.193 \\
\hline$\geq 38$ & $175(87.2)$ & $25(12.5)$ & & \\
\hline \multicolumn{5}{|l|}{ Birth weight } \\
\hline$<2.5 \mathrm{~kg}$ & $14(82.4)$ & $3(17.6)$ & $\begin{array}{l}1.39(0.37- \\
5.15)\end{array}$ & 0.616 \\
\hline $2.5-3.9 \mathrm{~kg}$ & 179(87.7) & $25(12.3)$ & & \\
\hline$\geq 4 \mathrm{~kg}$ & $10(71.4)$ & $4(28.6)$ & $\begin{array}{l}2.75(0.80- \\
9.39)\end{array}$ & 0.105 \\
\hline \multicolumn{5}{|l|}{ Jaundice in previous baby } \\
\hline Yes & $15(68.2)$ & $7(31.8)$ & $\begin{array}{l}3.50(1.30- \\
9.44)\end{array}$ & 0.013 \\
\hline No & 188(88.3) & $25(11.7)$ & & \\
\hline \multicolumn{5}{|l|}{ Time of initiation of first feed } \\
\hline$>1$ hours & $79(81.4)$ & $18(18.6)$ & $\begin{array}{c}2.25(1.05- \\
4.79)\end{array}$ & 0.036 \\
\hline \multicolumn{5}{|l|}{ Significant weight loss } \\
\hline Yes & $35(92.1)$ & $3(7.9)$ & $\begin{array}{l}0.5(0.14- \\
1.79)\end{array}$ & 0.294 \\
\hline No & $148(86.0)$ & $24(14.0)$ & & \\
\hline \multicolumn{5}{|l|}{ Rupture of membrane (ROM) } \\
\hline$\geq 18 \mathrm{hrs}$ & 11(91.7) & $1(8.3)$ & $\begin{array}{l}0.56(0.07- \\
4.51)\end{array}$ & 0.589 \\
\hline \multirow{2}{*}{\multicolumn{5}{|c|}{ Mother-infant ABO discordancy }} \\
\hline & & & & \\
\hline Yes & $21(70.0)$ & $9(30.0)$ & $\begin{array}{c}3.17(1.27- \\
7.87)\end{array}$ & 0.013 \\
\hline No & $148(88.1)$ & $20(11.9)$ & & \\
\hline \multicolumn{5}{|l|}{ Mother-infant Rh discordancy } \\
\hline Yes & $4(66.7)$ & $2(33.3)$ & $\begin{array}{l}3.05(0.53- \\
17.5)\end{array}$ & 0.22 \\
\hline No & $165(86.0)$ & $27(14.0)$ & & \\
\hline \multicolumn{5}{|l|}{ C-reactive protein } \\
\hline$<10$ & 151(87.3) & $22(12.7)$ & & \\
\hline$\geq 10$ & $14(63.6)$ & $8(36.4)$ & $\begin{array}{l}3.92(1.47- \\
10.42)\end{array}$ & $<0.006$ \\
\hline \multicolumn{5}{|l|}{ Mode of delivery } \\
\hline Caesarean section & 141 & 27 & $\begin{array}{l}2.14(0.78- \\
5.85)\end{array}$ & 0.136 \\
\hline Vaginal delivery & 62 & 5 & & \\
\hline
\end{tabular}




\begin{tabular}{|lccc|}
\hline Variables & Adjusted Odds Ratio & 95\% Conf. Interval & P-value \\
Jaundice in previous baby & 1 & & \\
No & 3.565 & $(1.10-11.51)$ & 0.034 \\
Yes & & & \\
Time of initiation of First feed $<1 \mathrm{hr}$ & 2.74 & $(1.10-6.90)$ & 0.007 \\
No & 1 & & \\
Yes & & & \\
CRP & 1 & $(1.23-12.73)$ & 0.021 \\
$<10$ & 3.962 & & \\
$\geq 10$ & & & \\
ABO Incompatibility & 1 & $(1.28-10.49)$ & 0.015 \\
No & 3.670 & & \\
Yes & & & \\
\hline
\end{tabular}

Table 3: Sensitivity and Specificity of TCB (TSB as Gold standard) SHB No SHB

\begin{tabular}{|l|l|l|}
\hline True positive 28 & $\begin{array}{l}\text { False positive } \\
31\end{array}$ & $\begin{array}{l}\text { Sensitivity }=96.5 \% \\
\text { Specificity }=84.6 \% \\
\text { PPV }=47.5 \%\end{array}$ \\
$\begin{array}{lll}\text { False negative } & \text { True negative } \\
171\end{array}$ & NPV $=99.4 \%$ \\
\end{tabular}

Kramer (TSB as Gold standard)

Sensitivity and Specificity of

SHB No SHB

\begin{tabular}{|c|c|}
\hline $\begin{array}{ll}\text { True positive } & 10\end{array}$ & $\begin{array}{l}\text { False positive } \\
3\end{array}$ \\
\hline $\begin{array}{l}\text { False negative } \\
22\end{array}$ & $\begin{array}{l}\text { True negative } \\
200\end{array}$ \\
\hline
\end{tabular}

Sensitivity $=31.2 \%$

Specificity $=98.5 \%$

$\mathrm{PPV}=76.9 \%$

$\mathrm{NPV}=90.0 \%$

\section{Discussion}

The prevalence of significant hyperbilirubinemia within the first 72 hours of life among neonates seen in our study was $13.6 \%$ with three participants $(1.3 \%)$ having serum bilirubin levels at/above exchange transfusion threshold. This prevalence seen was higher compared to those observed in other studies $(3,8,18)$ but this might be because we used the South African neonatal guidelines whose intervention threshold are slightly lower as compared to the other guidelines.

There is very scanty literature on significant jaundice within the first 72 hours of life but compared to our findings a study in Egypt looking at predictors of significant jaundice among well neonates without risk factors in the first 5 days found a prevalence of $16 \%$ (19) which was slightly higher than our finding considering they recruited neonates beyond 72 hours of age. 
More worrying from our finding is 3 participants with bilirubin levels at exchange transfusion threshold; these three had serum bilirubin levels of 332.3, 420 and $481.4 \mu \mathrm{mol} / \mathrm{l}$ before 60 hours of life. All the three had blood group discordance and positive history of jaundice in sibling needing treatment. These are example of neonates likely to be allowed home due to lack of risk assessment and predischarge screening for significant hyperbilirubinemia in LMICs.

Of our study participants $30 / 198(15.1 \%)$ mothers with blood group 0 gave birth to neonate with a different blood, this finding is similar to the one observed in Nigeria(20); 9/30 participants with ABO discordance developed SHB in our study. Significant hyperbilirubinemia (table 2) was independently associated with $A B O$ discordance (AOR 3.6, $\mathrm{Cl} 1.28-10.49 \mathrm{p} 0.015)$. This finding suggests possibility of $A B O$ associated hemolysis as one of the causes of SHB in our study population. This finding is in line with a systematic review that looked at risk factors for severe neonatal jaundice in LMIC (4).

Rhesus incompatibility is a known risk factor for significant hyperbilirubinemia $(4,8)$. In our study 6 mothers-infant pairs had Rh discordance; 2 participants developed significant hyperbilirubinemia. Whereas the odds of developing significant hyperbilirubinemia was high (table 1) in the bivariate analysis (OR3.05, Cl $0.53-17.5, \mathrm{p} 0.22$ ), it was not statistically significant, this can be explained by the small number of Rh discordant participants we had in our study. Also of note is the 4 mothers who had Rh discordance whose infants did not develop SHB one was a prime gravid while the three had received anti D immunoglobulin, this demonstrated the relevance of antenatal screening and prevention measures.

CRP $\geq 10 \mathrm{mg} / \mathrm{l}$ was independently associated with SHB (AOR 3.96, Cl 1.2-12.7 p 0.021) (table 2). Twenty two $(9.4 \%)$ of our study participants had CRP $>10 \mathrm{mg} / \mathrm{l}$, among them 9 had clinical sepsis as evidenced by fevers $>37.5^{\circ} \mathrm{C}$ with no explanation and one of them had SHB. Thirteen participants with elevated CRP did not have clinical signs for sepsis and none of them had obvious risk for sepsis or any perinatal stressors to explain the CRP. Of these; 8 had SHB of whom 3 had concurrent ABO discordance but for 5 (15.6\%) there was no identifiable reason for high CRP and SHB.

Whereas it is known that perinatal stressors including prolonged labour, meconium aspiration, birth asphyxia, intraventricular hemorrhage, induction of labour may be associated with elevated CRP in the first few days after birth (21-23) $15.6 \%$ of our study participants with elevated CRP and SHB did not have identifiable perinatal stressors. We concluded that sepsis could be responsible for this finding considering that sepsis in neonates tends to be associated with hemolysis and jaundice $(4,24)$. In view of the high mortality associated with neonatal jaundice of 1309.3 per 100,000 live births in the first 6 days of life (9) and sepsis as one of the major contributors to neonatal mortality in LMIC (25) a high index of suspicion is needs. Our finding of seemingly well neonate due for discharge having significantly elevated CRP is a phenomenon that needs further review.

Neonates whose mothers have had previously infants with jaundice were more likely to have SHB 7/22 (AOR 3.5, Cl 1.10-11.5, p 0.034) (table 2), of the 7 neonates with history of jaundice in previous sibling 5 had $\mathrm{ABO} / \mathrm{Rh}$ discordance while the other two no reason could be identified. This can be explained by the 
other familial causes of neonatal jaundice including G6PD deficiency, hemoglobinopathies and enzymopathies among others (4). History of jaundice in previous infant is a known risk factor for jaundice in subsequent infant (2).

Adequate enteral feeding facilitates excretion of bilirubin while inadequate favors increased enterohepatic circulation and jaundice (26). Majority $59.6 \%$ of our study participants were initiated on breast feeding within the first hour of birth. Among participant delivered per vaginal 55/67 (82.1\%) breast fed within the first hour compared to $83 / 168$ (49.4\%) delivered by cesarean section. Participants not fed within the first hour were fed between 2 hours and 18 hours of birth. Study participants who breast fed $\geq 1$ hour of birth were more likely to develop SHB 18/97 compared to those fed $<1$ hour of birth 14/138, (AOR 2.74, Cl 1.1-6.9 p 0.007) (table 2). This finding is similar to that observed in Zimbabwean study that looked at early initiation of breast feeding on jaundice (27). The importance of early initiation of breast feeding cannot be over emphasized.

Of the 235 study participant 210 had both birth weight and weight at enrollment verified. Thirty eight $38 / 210(18.1 \%)$ had significant weight loss which we defined as $\geq 75^{\text {th }}$ percentile in the application tool for monitoring weight loss in newborn (28). Of the participants breast fed $<1$ hour of birth 19/138 had significant weight loss compared to $19 / 97$ who fed $\geq 1$ hour of birth. Only $3 / 38$ of the participants with significant weight loss had SHB (table 1), this finding is contrary to findings from other studies that have demonstrated high weight loss being associated with significant hyperbilirubinemia $(4,5)$. The reason for our finding might lie in the fact that the number of participants with significant weight loss was small and most of the participants with risk for SHB did not have significant weight loss.

Majority of our study participants with significant hyperbilirubinemia $12(37.5 \%)$ the cause could not be ascertained. Whereas identification of the cause for significant hyperbilirubinemia is important in deciding the course of management and family counseling for future pregnancies, the cause may not be established in as high as $50 \%$ of cases $(29,30)$, in Uganda with a high prevalence of G6PD deficiency (31) and other hemoglobinopathies, it would be important to ascertain how much these contribute to SHB.

Transcutaneous bilirubin over the sternum identified majority of study participants with SHB 28/29 compared to visual inspection 10/32 (table 3 ). Transcutaneous bilirubinometry is steadily being accepted as modality for screening term neonates for hyper bilirubinemia $(2,32)$. It has been found to yield results that highly correlate with serum levels even among black African infants yet short turn-around time $(33,34)$.

Visual assessment for jaundice is a very well described process but its accuracy in determining the levels is very subjective that even specialist can wrongly estimate bilirubin level using the visual assessment $(5,32,35)$. In our study it had very low sensitivity and cannot be recommended for screening purpose (table 3).

\section{Conclusion}


Significant hyperbilirubinemia is prevalent among well neonates due for discharge. Transcutaneous bilirubinometry identifies majority of neonates with SHB. Delayed initiation of breast feeding is a risk factor for SHB. Well neonates with SHB without identifiable cause should be screened for sepsis.

Study limitation: majority of study participants were delivered by caesarian section hence our findings might not be very representative of neonates delivered vaginally. We could not do coombs test, blood cultures, film comment, G6PD assay, among others to confirm infection and hemolysis.

What is already known? Continued screening of all neonates for jaundice in necessary in order to identify those at risk. Transcutaneous bilirubinometry is a good screening tool for hyperbilirubinemia.

What this study adds? Visual assessment for jaundice is a poor tool in identifying neonates needing treatment for jaundice. Possibility of sepsis is heightened among well neonates with significant hyperbilirubinemia without identifiable cause for significant hyperbilirubinemia.

\section{List Of Abbreviations}

Rh: Rhesus

ABO: Blood groups A, B and O

CRP: C-reactive protein

LMICs: Low and Middle Income Countries

SCBU: Special Care Baby Unit

SHR: Significant Hyperbilirubinemia

TCB: Transcutaneous Bilirubin

TSB: Total Serum Bilirubin

WHO: World Health Organization

\section{Declarations}

Ethics approval and consent to participate: Ethical approval to conduct this study was obtained from the Makerere Colleague of Health Sciences Institution review board. Written informed consent was obtained from the parents of study participants.

Consent to publish: Not applicable

Availability of data and materials: The datasets used and/or analyzed during the current study are available from the corresponding author on reasonable request. 
Competing interest: None of the authors have any conflict of interest to declare.

Funding: This study received no external funding.

Authors' contribution: N.C collected and entered the data; she along with Y.A reviewed literature and did the write up. K.C and M.J reviewed the literature, methodology and write up. All authors approved the final version of this work.

Acknowledgement: The maternity unit and staff for their support during the study period. The mothers of the study participants for accepting to participate in the study.

\section{References}

(1) Slusher TM, Zamora TG, Appiah D, Stanke JU, Strand MA, Lee BW, et al. Burden of severe neonatal jaundice: a systematic review and meta-analysis. BMJ Paediatr Open 2017 Nov 25;1(1):e000105.

(2) Rennie J, Burman-Roy S, Murphy MS. Neonatal jaundice: summary of NICE guidance. BMJ 2010 10.1136/bmj.c2409;340(4):c2409.

(3) Tikmani SS, Warraich HJ, Abbasi F, et al. Incidence of neonatal hyperbilirubinemia: a populationbased prospective study in Pakistan. Trop Med Int Health 2010;15:502-7.

(4) Olusanya BO, Osibanjo FB, Slusher TM. Risk factors for severe neonatal hyperbilirubinemia in low and middle-income countries: a systematic review and meta-analysis. PLoS One 2015 Feb 12;10(2):e0117229.

(5) Olusanya BO, Kaplan M, Hansen TWR. Neonatal hyperbilirubinaemia: a global perspective. Lancet Child Adolesc Health 2018 Aug;2(8):610-620.

(6) Mwaniki MK, Atieno M, Lawn JE, Newton CR. Long-term neurodevelopmental outcomes after intrauterine and neonatal insults: a systematic review. Lancet 2012 Feb 4;379(9814):445-452.

(7) Shapiro SM. Bilirubin toxicity in the developing nervous system. Pediatr Neurol 2003 Nov;29(5):410421.

(8) Bhutani VK, Zipursky A, Blencowe H, Khanna R, Sgro M, et al. Neonatal hyperbilirubinemia and Rhesus disease of the newborn: incidence and impairment estimates for 2010 at regional and global levels. Pediatr Res 2013 Dec;74 Suppl 1:86-100.

(9) Olusanya BO, Teeple S, Kassebaum NJ. The Contribution of Neonatal Jaundice to Global Child Mortality: Findings From the GBD 2016 Study. Pediatrics 2018 Feb;141(2):e20171471.

(10) Burke BL, Robbins JM, Bird TM, Hobbs CA, Nesmith C, Tilford JM. Trends in hospitalizations for neonatal jaundice and kernicterus in the United States, 1988-2005. Pediatrics 2009 Feb;123(2):524-532. 
(11) Kuzniewicz MW, Escobar GJ, Newman TB. Impact of universal bilirubin screening on severe hyperbilirubinemia and phototherapy use. Pediatrics 2009 Oct;124(4):1031-1039.

(12) WHO. WHO Recommendations on Postnatal Care of the Mother and Newborn. Geneva: WHO October 2013.

(13) Greco C, Arnolda G, Boo NY, Iskander IF, Okolo AA, Rohsiswatmo R, et al. Neonatal Jaundice in Lowand Middle-Income Countries: Lessons and Future Directions from the 2015 Don Ostrow Trieste Yellow Retreat. Neonatology 2016;110(3):172-180.

(14) Nakimuli A, Nakubulwa S, Kakaire O, Osinde MO, Mbalinda SN, Nabirye RC, et al. Incidence and determinants of neonatal morbidity after elective caesarean section at the national referral hospital in Kampala, Uganda. BMC Res Notes 2015 Oct 30;8:624.

(15) Ballard JL, Khoury JC, Wedig K, Wang L, Eilers-Walsman BL, et al. New Ballard Score, expanded to include extremely premature infants. J Pediatr 1991 Sep;119(3):417-423.

(16) Kramer LI. Advancement of dermal icterus in the jaundiced newborn. Am J Dis Child 1969;118:4548.

(17) Horn AR, Kirsten GF, Kroon SM, Henning PA, Möller G, Pieper C, et al. Phototherapy and exchange transfusion for neonatal hyperbilirubinaemia: neonatal academic hospitals' consensus guidelines for South African hospitals and primary care facilities. S Afr Med J 2006 Sep;96(9):819-24.

(18) Maisels MJ, Gifford K. Normal serum bilirubin levels in the newborn and the effect of breast-feeding. Pediatrics 1986 Nov;78(5):837-843.

(19) Khairy MA, Abuelhamd WA, Elhawary IM, Mahmoud Nabayel AS. Early predictors of neonatal hyperbilirubinemia in full term newborn. Pediatr Neonatol 2019 Jun;60(3):285-290.

(20) Akanmu AS, Oyedeji OA, Adeyemo TA, Ogbenna AA. Estimating the Risk of ABO Hemolytic Disease of the Newborn in Lagos. J Blood Transfus 2015;2015:560738.

(21) Hofer N, Zacharias E, Muller W, Resch B. An update on the use of C-reactive protein in early-onset neonatal sepsis: current insights and new tasks. Neonatology 2012;102(1):25-36.

(22) Mjelle AB, Guthe HJT, Reigstad H, Bjorke-Monsen AL, Markestad T. Serum concentrations of Creactive protein in healthy term-born Norwegian infants 48-72 hours after birth. Acta Paediatr 2019 May;108(5):849-854.

(23) Perrone S, Lotti F, Longini M, Rossetti A, Bindi I, Bazzini F, et al. C reactive protein in healthy term newborns during the first 48 hours of life. Arch Dis Child Fetal Neonatal Ed 2018 Mar;103(2):163-166.

(24) Griffiths PD, Huntsman RG, Thomas CG. Neonatal jaundice from sepsis. BMJ 1964;1:7-8. 
(25) The Alliance for Maternal and Newborn Health Improvement (AMANHI) mortality study group. Population-based rates, timing, and causes of maternal deaths, stillbirths, and neonatal deaths in south Asia and sub-Saharan Africa: a multi-country prospective cohort study. Lancet Glob Health 2018;6:e1297308.

(26) Gourley GR. Breast-feeding, neonatal jaundice and kernicterus. Semin Neonatol 2002 Apr;7(2):135141.

(27) Gladys M, Mathilda Z, Zvanyadza G, Babill St. Early breast feeding initiation and incidence of severe jaundice in Chipinge district Zimbabwe. int J Contemp Pediatr 2017;4(6):1922-1926.

(28) AAP News. Tool monitors weight loss in breast fed babies. American Academy of Pediatrics 2015;36(2):27.

(29) Narang A, Gathwala G, Kumar P. Neonatal jaundice: an analysis of 551 cases. Indian Pediatr 1997 May;34(5):429-432.

(30) Sgro M, Campbell D, Shah V. Incidence and causes of severe neonatal hyperbilirubinemia in Canada. CMAJ 2006 Sep 12;175(6):587-590.

(31) Roh ME, Oyet C, Orikiriza P, Wade M, Mwanga-Amumpaire J, Boum Y,2nd, et al. Screening for Glucose-6-Phosphate Dehydrogenase Deficiency Using Three Detection Methods: A Cross-Sectional Survey in Southwestern Uganda. Am J Trop Med Hyg 2016 Nov 2;95(5):1094-1099.

(32) American Academy of Pediatrics Subcommittee on Hyperbilirubinemia. Management of hyperbilirubinemia in the newborn infant 35 or more weeks of gestation Pediatrics. Pediatrics 2004;114:297-316.

(33) Slusher TM, Angyo IA, Bode-Thomas F, Akor F, Pam SD, Adetunji AA, et al. Transcutaneous bilirubin measurements and serum total bilirubin levels in indigenous African infants. Pediatrics 2004 Jun;113(6):1636-1641.

(34) Chimhini GLT, Chimhuya S, Chikwasha V. Evaluation of transcutaneous bilirubinometer (DRAEGER JM 103) use in Zimbabwean newborn babies. Matern Health Neonatol Perinatol 2018 Jan 18;4:1.

(35) Moyer VA, Ahn C, Sneed S. Accuracy of clinical judgment in neonatal jaundice. Arch Pediatr Adolesc Med 2000 Apr;154(4):391-394. 